DOI: https://doi.org/10.24867/09BE06Bijelic

\title{
PRIMJENA DISTRIBUIRANIH ELEKTROENERGETSKIH RESURSA NA RJEŠAVANJE PREOPTEREĆENJA U SAVREMENIM ELEKTRODISTRIBUTIVNIM MREŽAMA
}

\section{THE SOLVING OF OVERLOADS IN ADVANCED POWER DISTRIBUTION NETWORKS USING DISTRIBUTED ENERGY RESOURCES}

Biljana Bijelić, Fakultet tehničkih nauka, Novi Sad

\section{Oblast - ELEKTROTEHNIKA I RAČUNARSTVO}

Kratak sadržaj - U teorijskom dijelu rada obrađen je pojam $i$ vrste distribuiranih elektroenergetskih resursa, kao i pojmovi „Non-wires alternatives “ $i$,, Smart Grid" koncepta. Praktičnim radom je pokazan uticaj ovih resursa na preopterećenje $u$ distributivnim mrežama uz pomoć komercijalnog softverskog rješenja za kontrolu $i$ upravljanje distributivnom mrežom. Dodatno, izvršen je proračun isplativosti odabranog rješenja $i$ analiza dobijenih rezultata.
\end{abstract}

Ključne reči: Distribuirani elektroenergetski resursi, DER, preopterećenje, „Non-wires alternatives“, solarne elektrane, vjetrogeneratori

Abstract - The theoretical part of this thesis deals with the concept and types of distributed energy resources, as well as the terms "Non-wires alternatives" and "Smart Grid" concept. Practical work has demonstrated the impact of these resources on overloading in distribution networks by using a commercial software solution for controlling and managing the distribution network. In addition, the cost-benefit analysis of the selected solution was performed and the results obtained were analyzed.

Keywords: Distributed energy resources, DER, overloading, Non-wires alternatives, solar power plants, wind generators

\section{UVOD}

Distributivni elektroenergetski sistem vrši raspodijelu i distribuiranje električne energije od prenosnih transformatorskih stanica i manjih elektrana do svakog potrošača $u$ obliku spremnom za upotrebu. Tradicionalni koncept prenosa električne energije, koji je uvijek bio jednosmjeran i koji je uvažavao tok proizvodnja - prenos - potrošnja značajno se mijenja uvođenjem distribuiranih izvora $\mathrm{u}$ distributivni elektroenergetski sistem.

U radu je definisan pojam „Smart Grid“ koncepta i opisane su prednosti koje ovakav vid upravljanja donosi. Obrađene su različite vrste distribuiranih elektroenergetskih resursa.

Uveden je i definisan pojam „Non-wires alternatives“. Dat je primjer proračuna i simulacije korišćenjem jednog komercijalnog softverskog rješenja koje se temelji na „Smart Grid“" konceptu i naprednim principima za kontrolu

\section{NAPOMENA:}

Ovaj rad proistekao je iz master rada čiji mentor je bio dr Nenad Katić, vanr. prof. i upravljanje distribuiranih elektroenergetskih resursa (DER) u distributivnim elektroenergetskim mrežama. Zatim je izvršen proračun isplativosti odabranog rješenja.

$\mathrm{Na}$ kraju rada, dat je konačan zaključak u vezi sa obrađenom temom i literatura korišćena prilikom izrade rada.

\section{SAVREMENA DISTRIBUTIVNA MREŽA}

Zbog ubrzanog razvoja, zaštite životne sredine i promjena $u$ tržištu električne energije, javljaju se novi uslovi za proizvodnju električne energije. To je sve više podstaknuto pojavom obnovljivih izvora električne energije, te se dolazi do novog koncepta električnih mreža.

Tradicionalan elektroenergetski sistem čine četiri osnovna podsistema: podsistem proizvodnje, podsistem prenosa, podsistem distribucije i podsistem potrošnje. Ovi podsistemi imaju jasno definisane granice [1].

Novi koncept distributivnih mreža unosi izvesne promene. I u ovakvim sistemima dio energije se proizvodi na tradicionalan način. To znači da jedan dio energije do krajnjih potrošača dolazi iz velikih elektrana preko podsistema prenosa i distribucije. Drugi dio energije se dobija iz malih proizvodnih jedinica koje su smještene u okviru distributivne mreže. Iz tog razloga, distributivne mreže nisu više pasivne, nego i one aktivno učestvuju u proizvodnji električne energije, pa se za moderne distributivne mreže kaže da su to aktivne distributivne mreže. U ovakvim distributivnim mrežama tok snage više nije jednosmjeran, od srednjenaponskih transformatorskih stanica ka potrošačima, već se snaga vraća i u drugom smjeru.

Struktura distiributivnih mreža se ubrzano mijenja. Takođe, ubrzan razvoj tehnologije i potreba za boljim kvalitetom električne energije postavljaju nove standarde u upravljanju distributivnim mrežama. Pojava dvosmjernog toka snage dovodi do potrebe za dvosmjernom komu-nikacijom, gdje na snagu stupaju informacione tehnologije i tako dolazimo do pojma pametnih distributivnih mreža, odnosno koncepta poznatog pod nazivom „Smart Grid“ rješenje.

Pametna mreža omogućava:

1. centralizovano razumijevanje stanja u dubini mreže, kompletan prikaz stanja mreže, optimizaciju distribuiranih i obnovljivih izvora, ali i mreže u cjelini,

2. značajno povećanje efikasnosti pogona današnjih mreža,

3. potrošačima da upravljaju svojom potrošnjom energije i uštede novac. 


\section{NAPREDNI PRINCIPI UPRAVLJANJA ELEKTRODISTRIBUTIVNIM MREŽAMA}

„Smart Grid“ koncept ne bi bio moguć bez naprednih softverskih alata za upravljanje distributivnim mrežama, ili kako ga komercijalno različite kompanije nazivaju „ADMS“ (eng. Advanced Distribution Management System).

To je savremeni softverski sistem koji omogućava obavljanje tehničkih poslova u distributivnom preduzeću na efikasan i optimalan način [2].

\subsection{Distributivne mreže sa distribuiranim elektroenergetskim resursima}

Savremene distributivne mreže suočavaju se sa sve većim brojem distribuiranih elektroenergetskih resursa.

U distribuirane elektroenergetske resurse se ubrajaju:

1. Fotonaponske elektrane

2. Vjetrogeneratori

3. Mikroturbine

4. Gorivne ćelije

5. Distribuirana skladišta energije

6. Baterije akumulatora

7. Električni automobili

8. Mikromreže

„Demand Response“ programi:

„Demand Response“ može da se definiše kao promjena u korišćenju električne energije od strane krajnjih potrošača i odstupanje od njihovih ustaljenih oblika potrošnje kao odgovor na promjene u cijeni električne energije ili u skladu sa pravilima drugih komercijalnih programa.

\subsection{Definisanje pojma „Non-wires alternatives“}

„Non-wires alternatives” se definiše kao investiranje u električnu mrežu ili projekte koji koriste netradicionalna prenosna i distributivna rješenja, kao što su distribuirani generatori, skladišta energije, energetska efikasnost, i softver za upravljanje i kontrolu mreže, da odlože ili zamijene potrebu za nadogradnjom, kao što su prenosni i distributivni transformatori, redukujući opterećenje na nivou podstanica ili električnog kola [3].

\subsection{Definicija sistema za upravljanje distribuiranim elektrenergetskim resursima}

Definicija sistema za upravljanje distribuiranim elektroenergetskim resursima (eng. Distributed Energy Resource Management System - DERMS) sistema koja je usvojena prilikom pisanja rada:

„DERMS“ teži upravljanju naponima, regulisanju napona i kontroli DER kao što su skladišta energije, solarni sistemi i električna vozila. Kompanije koje vrše upravljanje DER nemaju pristup aparatima i energetskim uređajima iza brojila, zato se one fokusiraju na sisteme kao što su skladišta energije u transformatorskim stanicama, solarne nadstrešnice nad parkiralištima, skladišta energije [4].

„Virtuelne elektrane“ (eng. Virtual Power Plant - VPP) nastaju spajanjem više DER koji djeluju kao jedinstven entitet na tržištu električne energije. Agregator upravlja sa više distribuiranih resursa zajedno kreirajući virtuelnu elektranu znatnog kapaciteta i zapravo predstavlja softver koji operiše virtuelnom elektranom.
Kao što je prethodno istaknuto, za „DERMS“ kao softver za upravljanje DER smatraće se sistem koji ne upravlja resursima iza brojila, niti se bavi upravljanjem proizvodnim resursima uz potrošače. „DERMS“ uzima u obzir postojanje i uređaja iza brojila i proizvodnih potrošača, ali i virtuelnih elektrana, ali se ne ograničava, niti usko bavi nekima od njih.

Komunicirajući sa agregatorom „DERMS“ indirektnim putem šalje informacije i zahtjeve distribuiranim resursima koji se nalaze u sklopu virtuelne elektrane. Jedan ovakav softver ima informaciju o stanju svih DER u mreži i vrši komandovanje uzimajući u obzir zahtjeve za proizvodnjom i potrošnjom cjelokupne mreže. Imajući uvid u cjelokupno stanje mreže omogućava da manipulacija ovim resursima ne dovede do dodatnih narušenja u mreži. Da bi se to omogućilo, jedna od najbitnijih osobina svih DER resursa za „DERMS“ je njihova fleksibilnost.

Fleksibilnost podrazumijeva informaciju o trenutnoj vrednosti nekog DER, ali i za koliko DER može da smanji ili poveća aktivnu ili reaktivnu snagu koju odaje u mrežu.

Može se reći da, za razliku od softvera za upravljanje virtuelnim elektranama, „DERMS“ mora imati mnogo složeniju funkcionalnost i mnogo širu upotrebu.

\section{RJEŠAVANJE PROBLEMA PREOPTEREĆENJA}

Za test primjer izabrana je nebalansirana šema jednog dela severnoameričke mreže. Posmatranja su vršena na primjeru transformatorske stanice sa dva napojna dvonamotajna transformatora $69 / 12.5 \mathrm{kV} / \mathrm{kV}$. Za test fider uzet je primjer fidera koji ima jedan vjetrogenerator i dvije baterije za skladištenje električne energije. I vjetrogenerator i baterije za skladištenje energije su u vlasništvu elektrodistributivne kompanije koja vrši isporuku električne energije ka potrošačima. Vjetrogenerator je povezan na mrežu preko invertora, što omogućava upravljivost ovog vjetrogeneratora. Razmatrani fider ima 2605 potrošača, a distributivnim transformatorima $12.5 / 0.2 \mathrm{kV} / \mathrm{kV}$ vrši se isporuka energije do krajnjih potrošača. Sa susjednim fiderima transformatorske stanice povezan je sa po dva normalno otvorena prekidača.

$\mathrm{Na}$ fideru sa vjetrogeneratorom i baterijama za skladištenje električne energije uočena je pojava preopterećenja.

Razmatrana su 2 načina rješavanja problema. Prvi način je korišćenjem komercijalnog „ADMS“ softverskog rešenja bez „DERMS“ modula, dok je u drugom slučaju problem preopterećenja rešen uz pomoć implementiranog „DERMS“ modula

\subsection{Korišćenje „ADMS“ rješenja bez „DERMS“ modula}

Normalna radna struja koju kablovi na razmatranom dijelu sekcije mogu da podnesu je 240A. U trenutku preopterećenja, struja dostiže vrijednost od $285 \mathrm{~A}$, što izaziva reagovanje relejne zaštite i otvaranje prekidača na početku fidera. U tom slučaju, 2605 potrošača ostaje bez napajanja.

Brzom reakcijom operatera, koji uz pomoć softvera prepoznaje da nije došlo do kvara u mreži, već ispada zbog preopterećenja, vrši se slanje ekipa na teren. Ekipe izvršavaju prekidačke instrukcije rasterećenja mreže 
predložene od strane „ADMS“ funkcije „Rekonfiguracija mreže“, odnosno preraspodjelu opterećenja sa razmatranog fidera na dva susjedna fidera. Zatvaranjem normalno otvorenih prekidača prema susjednim fiderima, kao i zatvaranjem prekidača na početku fidera vraća se napajanje potrošačima i vrijednost struje na preopterećenom dijelu sekcije smanjuje na 230A.

Za rješavanje problema na ovaj način bio bi potreban „ADMS“ softver za prepoznavanje problema, predlaganje akcija potrebnih za rasterećenje, kao i angažovanje dvije ekipe, koje izvršavaju predložene akcije. S obzirom da se radi o mreži na američkom tržištu, potrebno je izračunati penale koje će distributivno preduzeće isplaćivati potrošačima usljed ostanka bez napajanja. Ukupno trajanje bezanaponske pauze za potrošače, tokom rješavanja problema preopterećenja i izvršenja neophodnih prekidačkih akcija, bilo bi oko 30 minuta.

Da bi se riješio problem, koristio bi se radni proces „Lokalizacija kvara, izolacija i restauracija napajanja” (FLISR - Fault Location, Isolation and Supply Restoration). Potrebno je poznavanje modela svih elemenata mreže, i raspoloživost baznih funkcionalnosti: „Tokovi snaga“ i ,Estimacija stanja“.

\subsection{Korišćenje „ADMS“ rješenja sa implementiranim „DERMS“ modulom}

„ADMS“ rješenje sa implementiranim „DERMS“ modulom ima brojne dodatne funkcionalnosti, poput praćenja i kontrole stanja distributivnih resursa u mreži, korišćenja DER prilikom rješavanja problema preopterećenja i inverznog toka snage uz pomoć funkcije „Rasterećivanja mreže“, a posebno funkcionalnost koja je veoma napredna i korisna za upravljanje DER u mreži je „Upravljanje ograničenjima u nastupajućem periodu“ (eng. Lookahead Constraint Management - LACM).

Za rješavanje ovog problema uz pomoć DER resursa korišćena je „LACM“ funkcionalnost.

Iako funkcija može da prati i prognozira stanje u mreži do $72 \mathrm{~h}, \mathrm{u}$ ovom slučaju praćenje je vršeno za 24h, radi dobijanja što boljih rezultata. Posmatrajući dijagram opterećenja na fideru u toku $24 \mathrm{~h}$, vidi se da se može očekivati značajno preopterećenje dva puta u toku dana, koje može dovesti do prorade zaštite od preopterećenja i ispada za veliki broj potrošača.

Funkcija „LACM“ na bazi prognoziranog dnevnog dijagrama opterećenja vrši izbjegavanje preopterećenja aktivirajući distribuirane elektroenergetske kapacitete u mreži.

S obzirom da se očekuje da se preopterećenje javi 2 puta u toku dana, funkcija „LACM“ kao izvore za razrješenje problema navodi različite resurse.

U prvom slučaju, napunjenost baterija je $80 \%$, što znači $1200 \mathrm{kWh}$, a brzina njihovog pražnjenja je $500 \mathrm{~kW}$, što pri datom naponu daje struju od 23A, po bateriji. Kako je period preopterećenja od $600 \mathrm{~kW}$ u trajanju od oko $2 \mathrm{~h}$, slijedi da baterije imaju dovoljno kapaciteta da pokriju preopterećenje.

U drugom periodu razmatranog dana preopterećenje je veće nego u prvom slučaju. U ovom trenutku kapacitet baterija, čija napunjenost sada iznosi 33\%, nije dovoljan da se pokrije očekivano preopterećenje, te stoga „LACM“ funkcija šalje signal regulatoru na vjetrogeneratoru od koga se zahtijeva da promijeni injektiranje u mrežu sa $200 \mathrm{~kW}$ na $1000 \mathrm{~kW}$ u trajanju od $2 \mathrm{~h}$. Kako se u tom periodu očekuje da će duvati vjetar brzinom oko $35 \mathrm{~km} / \mathrm{h}$, slijedi da će vjetrogenerator moći da nadomjesti potrebe za električnom energijom.

Simulacijom ovakvih događaja, koji ne moraju striktno da odgovaraju događajima u stvarnosti, testirana je upotreba „DERMS“ modula na test mreži.

Funkcija „LACM“ omogućila je razrješenje problema u budućnosti, odnosno dovela do izbjegavanja problema $\mathrm{u}$ budućnosti. Na taj način nije došlo ni do preopterećenja, niti do ispada u snabdijevanju potrošača, odnosno neisporučene električne energije.

U ovom slučaju bilo je potrebno aktiviranje automatskog režima funkcije „LACM“, razvijene u okviru „DERMS“ modula odabranog komercijalnog softverskog rješenja. $\mathrm{Na}$ ovaj način, pored implementacije „DERMS“ modula uz „ADMS“ softver, nisu bila potrebna dalja ulaganja $\mathrm{u}$ aktiviranje ekipa na terenu, niti troškovi u vidu penala za neisporučenu električnu energiju.

\section{COST - BENEFIT ANALIZA}

U radu su testirana dva slučaja rješavanja problema preopterećenja. U oba primjera bilo je potrebno postojanje softvera za praćenje, kontrolu i upravljanje distributivnom mrežom.

Procjena za cijenu komercijalnog softverskog rješenja bez „DERMS“ modula za upravljanje i kontrolu distributivne mreže, zajedno sa inženjeringom i puštanjem u rad, je oko $\$ 150,000$.

Procjena za cijenu komercijalnog softverskog rješenja za upravljanje i kontrolu distributivne mreže sa „DERMS“ modulom je oko $\$ 180,000$.

U prvom slučaju je došlo do ispada i dio potrošača je ostao bez napajanja. Cijena za neisporučenu električnu energiju je definisana regulatornim procesima jedne države, i razlikuje se za svaku američku državu pojedinačno. Štete za snabdjevača (penali) i potrošače se izražavaju u vidu virtuelne ,cijene“ neisporučene električne energije, odnosno ukupna šteta koja nastaje se podijeli sa brojem neisporučenih kWh i dobija prosečna „cijena“. Cijena neisporučene električne energije je obično oko 5 - 10 puta veća u slučaju domaćinstava, dok kod komercijalnih i industrijskih potrošača može biti i nekoliko desetina puta veća od cijene isporučene električne energije. Za potrebe proračuna usvojena je referentna cijena isporučene električne energije od oko $12 \mathrm{c} \$ / \mathrm{kWh}$, a za neisporučenu električnu energiju (penali) se može uzeti oko 8 puta veća cijena (oko $1 \$ / \mathrm{kWh}$ ), jer su na fideru priključena većinom domaćinstva, ali ima i komercijalne potrošnje.

Za povratak napajanja funkcija je procijenila vrijeme potrebno za povratak napajanja u trajanju od 33min (eng. ETR- Estimated Time of Restoration), odnosno okvirno $30 \mathrm{~min}$.

To znači da u slučaju ispada od $4000 \mathrm{~kW}$, u trajanju od pola sata, neisporučena električna energija bi bila oko 2000 $\mathrm{kWh}$, a kompanija bi morala da plati penale u vrijednosti od oko $\$ 2,000$ po svakom ispadu. Ukoliko se pretpostavi da se ovakvi ispadi javljaju jednom do dva puta mjesečno, na primjer 20 puta godišnje, to daje vrednost penala od oko $\$ 40,000$ u trajanju od godinu dana. 
Kako je trošak koji se ima za uvođenje „DERMS“ modula $\$ 180,000$ i trošak korišćenja tokom 10 godina (vijeka trajanja) oko 3\% godišnje, odnosno $\$ 54,000$, ukupan trošak posedjovanja sistema (eng. Total Cost of Ownership TCO) je \$234,000, bez uvažavanja svođenja (eng. discount) vrijednosti novca na početni ili krajnji period, što bitno ne mijenja rezultate zbog manjeg iznosa u vremenu.

Sa druge strane, benefit koji bi se ostvario na desetogodišnjem nivou je oko $\$ 400,000$ hiljada, bez uvažavanja svođenja (eng. discount) vrednosti novca na početni ili krajnji period, što bitno ne mijenja rezultate, čime slijedi da je:

$$
\frac{\text { Cost }}{\text { Benefit }}=\frac{\$ 234,000}{\$ 400,000}=0,585
$$

To znači da je period povraćaja sredstava:

$$
\frac{\text { Cost }}{\text { Benefit }} \times \text { Time }=0,585 \times 10=5,85 \text { godina }
$$

Odnos između troškova i benefita ima vrijednost 0.58 , te se može zaključiti da je sa ekonomske strane ulaganje u softver za upravljanje distribuiranim resursima isplativo.

\section{ZAKLJUČAK}

U ovom radu predstavljeno je uvođenje novih tehnologija u elektrodistributivni sistem. Opisani distribuirani elektroenergetski izvori su uređaji današnjice, a njihova najveća iskoristivost je tema bliske budućnosti, kome se brzo približavamo. Činjenica je da će tih resursa biti sve više $i$ da će upravljanje ovim resursima biti sve složenije. Stoga potreba za uvođenjem pametnih i naprednih softverskih rješenja koja mogu da podrže kontrolu i upravljanje DER u mreži postaje prioritet za upravljanje savremenim distributivnim mrežama.

Porast broja stanovnika na Zemlji, kao i ubrzan tempo života dovodi do sve većih potreba za električnom energijom. Neobnovljivi resursi na planeti se troše i utiču na klimatske promjene, te je upotreba obnovljivih resursa neophodna. Kako su zahtjevi za potrošnjom električne energije veći, dolazi i do problema preopterećenja koji je bio predmet ovog rada. Pokazano je kakav benefit donosi upotreba distribuiranih resursa. Na taj način, bez novih ulaganja u ojačavanje distributivne mreže, riješen je problem preopterećenja. Međutim, taj benefit nije samo ekonomski, podsticaj korišćenja i upotrebe obnovljivih izvora je ekološki od krucijalnog značaja, zbog očuvanja životne sredine i kvaliteta života.

\section{LITERATURA}

[1] Milorad Svorcan: „Uticaj distribuiranih generatora na naponske prilike $u$ distributivnim mrežama i podešenje podnaponske i prenaponske zaštite“, diplomski - master rad, Fakultet tehničkih nauka, Novi Sad, 2014.

[2] Nenad A. Katić, predavanja iz predmeta „Menadžment sistemi u elektroenergetici EMS i DMS“, Fakultet tehničkih nauka, Novi Sad, 2018.

[3] E4TheFuture, PLMA, SEPA: „Non-Wires Alternatives - Case studies from leading U.S. Projects", novembar, 2018.

[4] https://sepapower.org/, decembar 2019.

\section{Kratka biografija:}

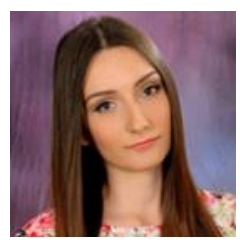

Biljana Bijelić rođena je u Bijeljini 1995. godine. Osnovne studije završila je na Fakultetu tehničkih nauka 2018. godine iz oblasti Elektrotehnike i računarstva Elektroenergetski sistemi. Master rad na istom fakultetu smjer Elektroenergetika Elektroenergetski sistemi odbranila je 2020. godine.

Kontakt: biljanabijelic1995@gmail.com 